\title{
Modification of Polycarbonate Terminals with Benzophenone Derivative via Transesterification
}

\author{
Yoichiro Makimura, Eri Yoshida, and Toshio Kitao \\ Department of Polymer Science and Engineering, Faculty of Textile Science, \\ Kyoto Institute of Technology, Matsugasaki, Sakyo, Kyoto 606, Japan
}

(Received July 22, 1996)

\begin{abstract}
Reaction of PC with 2-hydroxy-4-(2-hydroxyethoxy)benzophenone (HHEBP) was carried out in the presence of $\mathrm{FeCl}_{3}$ in a torque rheometer at $255^{\circ} \mathrm{C}$. The reaction rapidly proceeded and conversion was more than $80 \%$ within $5 \mathrm{~min}$. HHEBP reacted quantitatively except for the amount of HHEBP vaporized. A film of this product showed high weather-proof on weather-o-test when compared to typical PC with no benzophenone derivatives or PC containing HHEBP obtained by the control experiment.

KEY WORDS Polycarbonate / Benzophenone Derivative / Torque Rheometer / Transesterification / Weatherability / Ultra-Violet Stabilizer /
\end{abstract}

Among thermoplastic polymers, the aromatic polycarbonate, synthesized from 2,2-bis(4-hydroxyphenyl)propane and diphenylcarbonate (or phosgene) and commonly designated as Bisphenol A polycarbonate, has been used in a wide range of academic studies and commercial applications because of its excellent optical, thermal and mechanical properties ${ }^{1,2}$ The large inherent birefrigence in connection with transparent appearance brings great advantages in studying the structureproperty relationship of bulk bodies such as stressinduced anisotropy of polymeric materials. ${ }^{3}$ In addition, its high glass transition temperature, $160^{\circ} \mathrm{C}$, and very low secondary relaxation temperature around $-100^{\circ} \mathrm{C}$ make this polymer very tough at ordinary temperatures. $^{4,5}$ Consequently, Bisphenol A polycarbonate is useful as material. ${ }^{6}$

This high performance polycarbonate, however, is known to be sensitive to UV and visible light. ${ }^{7-14}$ Prolonged exposure to UV and/or visible light results in the formation of yellowish coloring groups due to rearrangement of chemical structure. One of the mechanisms may be photo-induced Fries rearrangement between an oxygen in carbonate linkage and adjacent phenyl group which subsequently forms diphenyl benzophenone sequence in the polymer. ${ }^{7}$ Furthermore photo degradation of PC resulted from chain oxidation. ${ }^{12}$ In commercial applications a small amount of 2-hydroxybenzophenone or its derivative has always been dispersed in the polycarbonate to prevent the photo-induced degradation. ${ }^{15}$ Unfortunately most UV stabilizers, benzophenone derivatives, are immiscible to polycarbonates and tend to bleed out. Immobilization of benzophenone derivatives onto polycarbonate may thus be expected to prolong the life of this useful polymer. ${ }^{16}$

Reactive processing technique has begun to attract notice in the field of polymer engineering, because it can simultaneously carry out both chemical reaction and fabrication in a single processing instrument. ${ }^{17}$ Various polymeric materials have been conveniently developed using this technique. Most studies on reactive processing, however, have dealt with the improvement of phase stability of polymer alloys, ${ }^{18,19}$ with few exceptions such as polymerization-processing of styrene ${ }^{20}$ and methylmethacrylate ${ }^{21}$ and functionalization of polymers. ${ }^{22}$ No paper describes the functionalization of polycarbonate by reactive processing.

In the present study, transesterification between polycarbonate and 2-hydroxybenzophenone with a hydroxyethoxy substituent was conducted in a torque rheometer as a model experiment of reactive processing for the immobilization of UV stabilizer onto the terminal of Bisphenol A polycarbonate in an actual twin screw extruder. The products were characterized as functions of processing variables such as mixing rate, reaction time and temperature.

\section{EXPERIMENTAL}

\section{Materials}

Bisphenol A polycarbonate (PC), supplied by Idemitsu Petrochemical Co., Ltd., was dried at $120^{\circ} \mathrm{C}$ for $12 \mathrm{~h}$ or longer before use. 2-Hydroxy-4-(2-hydroxy-ethoxy)benzophenone (HHEBP) manufactured by BASF was recrystallized from methanol. Ferric chloride anhydride (analytical-grade) purchased from Nacalai Tesque was used as received.

\section{Instrumentation}

As illustrated in Figure 1, transesterification between PC and HHEBP was conducted in the mixing chamber of a torque rheometer (HAAKE Rheocord 90) of 70 $\mathrm{cm}^{3}$. Processing variables such as temperature, mixing time and mixing speed were accurately controlled and material temperature and torque were recorded as functions of mixing time. PC modified in the rheometer were subjected to the following characterizations: ${ }^{1} \mathrm{H}$ NMR spectra were recorded on JEOL JNM-EX270. UV spectra were taken on Hitachi U-3210. Gel permeation chromatography (GPC) was performed at $40^{\circ} \mathrm{C}$ at 1.0 $\mathrm{ml} \min ^{-1}$ with SSC-7000 VHT-GPC (Senshu Scientific Co., Ltd.), equipped with Shodex $\mathrm{KF} 804 \mathrm{~L} \times 3$ columns. The data obtained were converted to $M_{n}$ and $M_{w}$ being calibrated with polystyrene standards. Weathering tests were carried out in a weather-o-meter by Daipla Co., Ltd.. The weathering test was programed using 


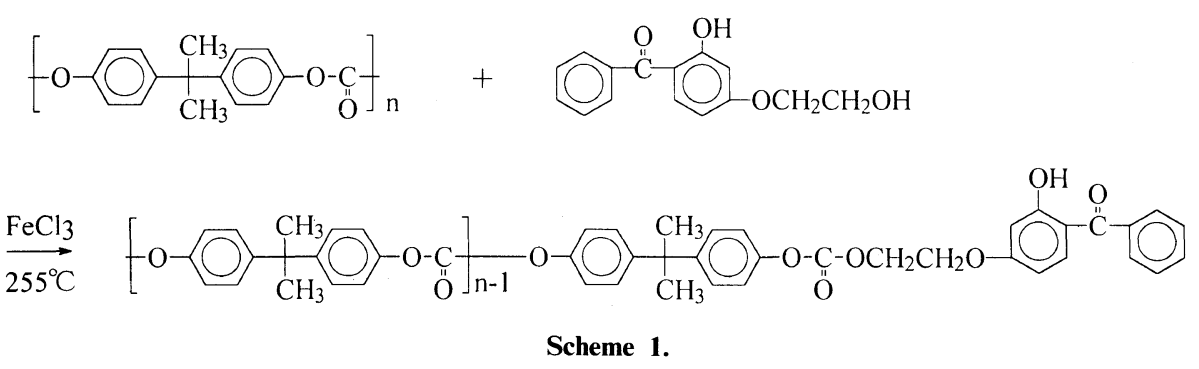

three different modes in a day: dry mode, at $30 \% \mathrm{RH}$ at $63^{\circ} \mathrm{C}$ for $16 \mathrm{~h}$ under the irradiation of halogen light $\left(80.0 \mathrm{~mW} \mathrm{~cm}^{-2}\right)$, damp mode, at $98 \% \mathrm{RH}$ at $30^{\circ} \mathrm{C}$ for $6 \mathrm{~h}$ under irradiation, and dark mode, at $70 \% \mathrm{RH}$ at $63^{\circ} \mathrm{C}$ for $2 \mathrm{~h}$. Specimens were rinsed with water for $5 \mathrm{~s}$ before and after the damp mode.

\section{Procedure}

$60.0 \mathrm{~g}$ PC (approximately $70 \mathrm{vol} \%$ of the mixing chamber) were loaded in two stages in every experiment: At first $40 \mathrm{~g}$ PC loaded in the mixing chamber held at $255^{\circ} \mathrm{C}$ were melted completely and then the rest was added. The kneading lasted for $4.5 \mathrm{~min}$ until the torque went down and leveled off. $0.6 \mathrm{~g}$ HHEBP and $0.6 \mathrm{mg}$ $\mathrm{FeCl}_{3}(0.1 \mathrm{~mol} \%$ to HHEBP $)$ were added again and the kneading was continued at a mixing speed of $30 \mathrm{rpm}$. After prescribed period of time, the operation was stopped. The products were immediately taken out from the chamber, quenched in $\mathrm{N}_{2}$ atmosphere and cast into thin films on a thin glass plate from methylenedichloride. As a control, a piece of PC film containing an equivalent amount of unreacted HHEBP and $\mathrm{FeCl}_{3}$ was prepared by casting from methylene dichloride.

\section{RESULTS AND DISCUSSION}

The reaction of PC with HHEBP is shown in Scheme 1.

The two-stage loading of PC may be responsible for a couple of the sharp peaks found at 1.3 and $2.7 \mathrm{~min}$ in the torque-time relation shown in Figure 1. The mixing torque decreases monotonically and then levels off beyond $4 \mathrm{~min}$, indicating the complete melting of PC loaded in the chamber. A sudden decrease at $4.5 \mathrm{~min}$ corresponds to the stopping of the rotor. Again the mixing was kept running at the same speed of $30 \mathrm{rpm}$ for $10 \mathrm{~min}$ or longer.

Figures 2 and 3 show the UV spectra of the control and product, respectively. Both specimens gave four characteristic absorption peaks; two sharp peaks at 264 and $272 \mathrm{~nm}$, a broad one around $328 \mathrm{~nm}$ and a shoulder at $287 \mathrm{~nm}$. The former two may be assigned to the phenyl and carbonyl groups of PC, whereas the latter two can be attributable to the phenolic hydroxy and carbonyl groups in HHEBP. After being reprecipitated from methylenechloride, the control had only two sharp absorption at 264 and $272 \mathrm{~nm}$, indicating that HHEBP in the control was completely eliminated from the specimens. The reaction product still gave similar absorption trace where peak intensities were almost unchanged. The conversion of HHEBP was estimated as $63 \%$ from the intensity ratio of absorption at $328 \mathrm{~nm}$ before and after the reprecipitation of the product.

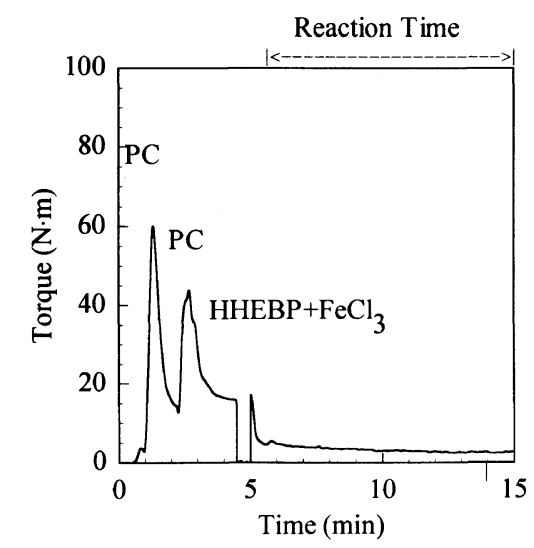

Figure 1. Torque curve of the reaction of PC $(60.0 \mathrm{~g})$ with HHEBP $(0.967 \mathrm{~mol} \%)$ in the presence of $\mathrm{FeCl}_{3}(0.10 \mathrm{~mol} \%)$ at $30 \mathrm{rpm}$ at $255^{\circ} \mathrm{C}$

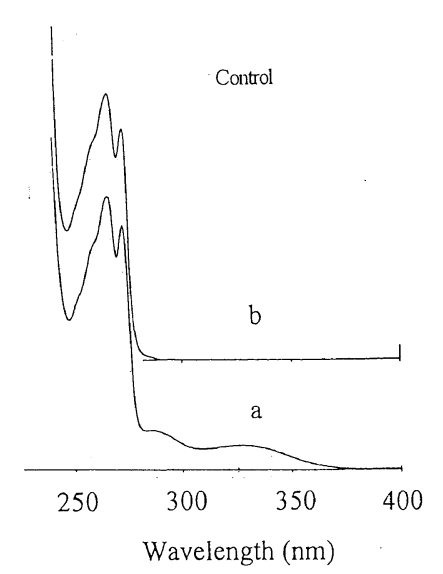

Figure 2. UV spectra of the control before (a) and after (b) purification.

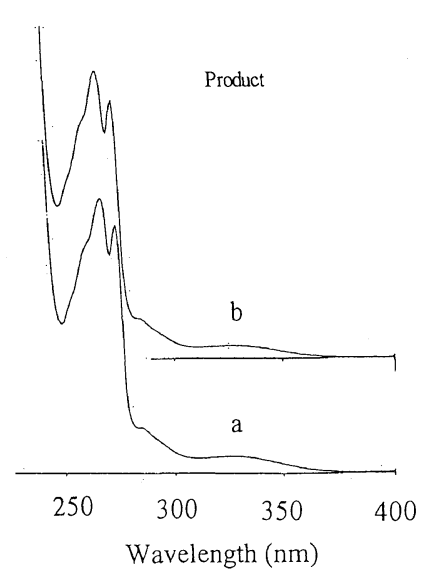

Figure 3. UV spectra of the product before (a) and after (b) purification. 
GPC curves were determined with a $254 \mathrm{~nm} \mathrm{UV}$ detector and are shown in Figure 4. The control gave a bimodal trace consisting of a larger peak from PC at $1410 \mathrm{~s}$ and much smaller one at $1920 \mathrm{~s}$ of retention: The former certainly comes from PC while the latter from free HHEBP. A unimodal curve obtained for the reaction product suggests that the reaction in the torque rheometer resulted in a small decomposition of $\mathrm{PC}$ because the number average molecular weights estimated for the control and the product were 29300 and 23700 , respectively. This implies that the transesterification of PC with monofunctional HHEBP in the mixing chamber resulted in molecular scission of $\mathrm{PC}$ in random manner. This is very natural because the transesterification between PC and monofunctional HHEBP with smaller molecular weight proceeds in accordance with the scheme 1 and should make the average molecular weight of the

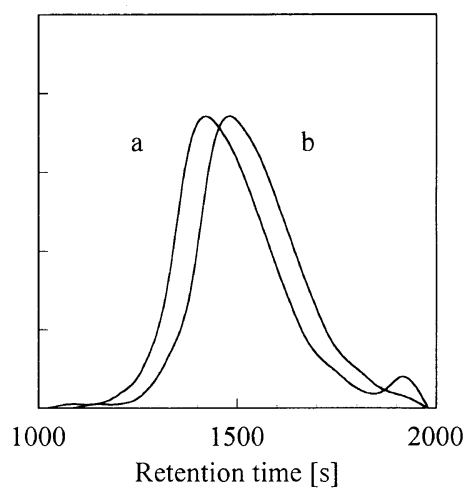

Figure 4. GPC curves measured with UV detection at $254 \mathrm{~nm}$ of the control (a), and product (b). system smaller.

Instead of the $254 \mathrm{~nm}$ UV detector, GPC curves were recorded with a UV detector of which characteristic wave length was $325 \mathrm{~nm}$. The results are shown in Figure 5. Only an absorption was recorded at $1920 \mathrm{~s}$ for the control specimen. The reaction product had a broad absorption over the wide range from 1250 to $1800 \mathrm{~s}$ in addition to a small peak around $1920 \mathrm{~s}$. This suggests that HHEBP in the product was chemically bonded with PC chains, while in the control merely dispersed in the matrix of PC. The conversion of HHEBP in the product was estimated to be $64 \%$ from these UV absorption intensities.

The chemical structure of the reaction product was confirmed with ${ }^{1} \mathrm{H}$ NMR. ${ }^{1} \mathrm{H}$ NMR spectra of the control and is shown in Figure 6. A couple of doublet signals at 7.18 and $7.24 \mathrm{ppm}$ could be assigned to the

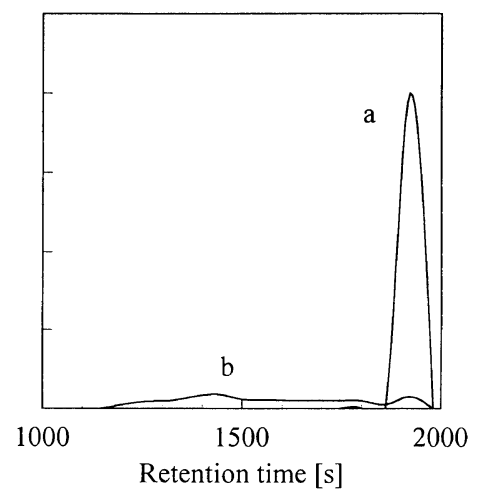

Figure 5. GPC curves measured with UV detection at $325 \mathrm{~nm}$ of the control (a), and the product (b).
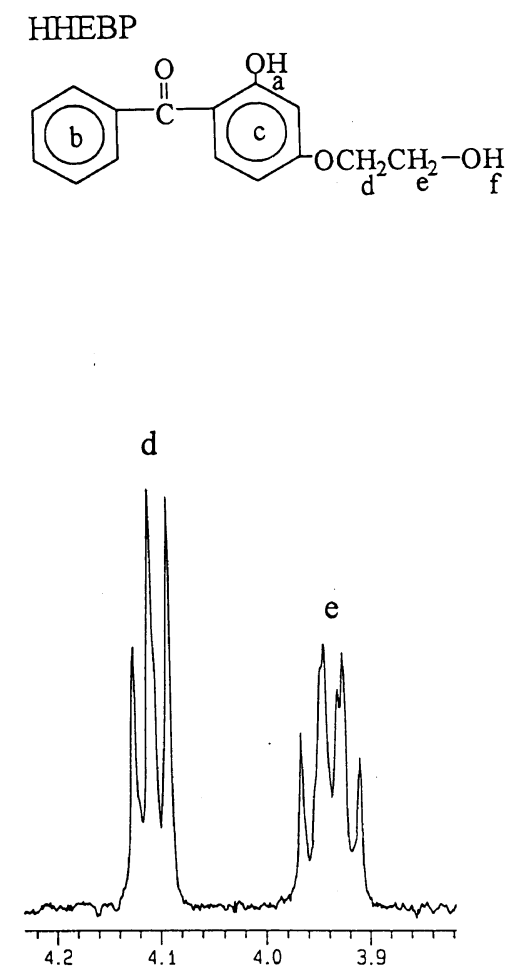

a
PC
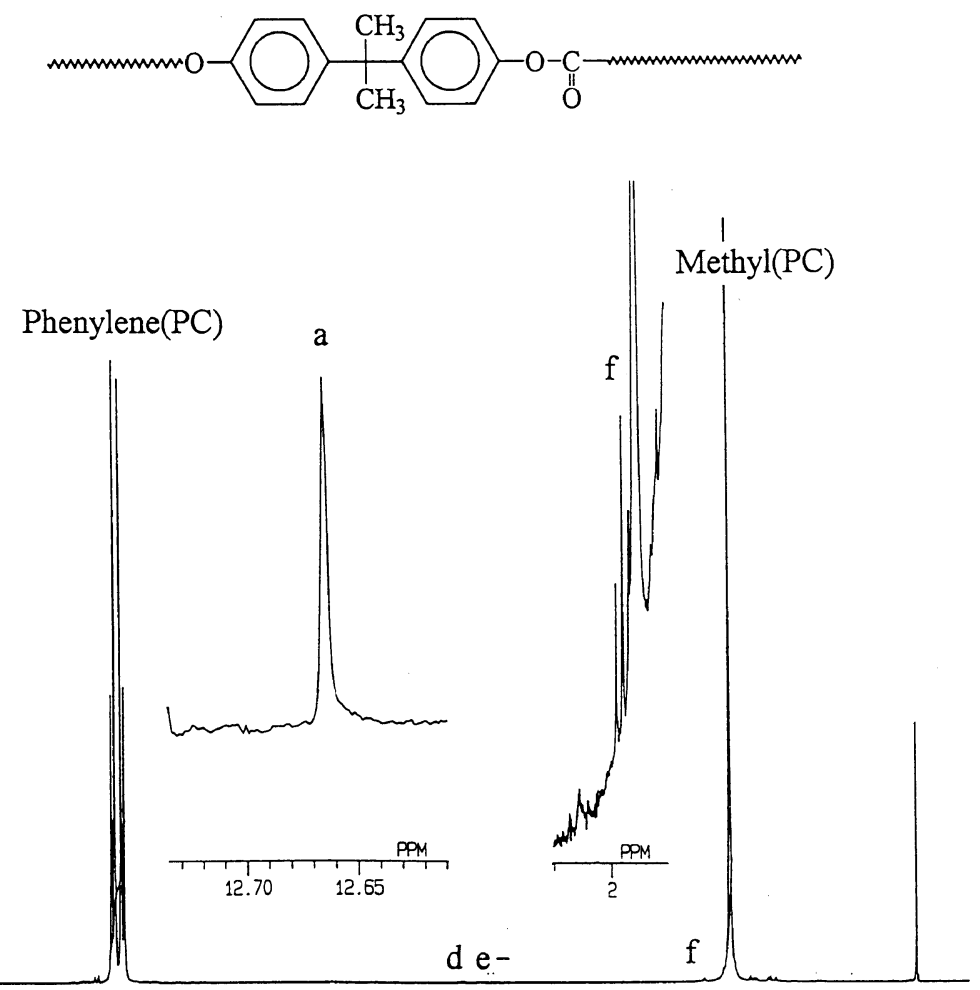

$\int_{0}^{P P M}$

Figure 6. ${ }^{1} \mathrm{H}$ NMR spectra of the control (solvent: $\mathrm{CDCl}_{3}$ ). 

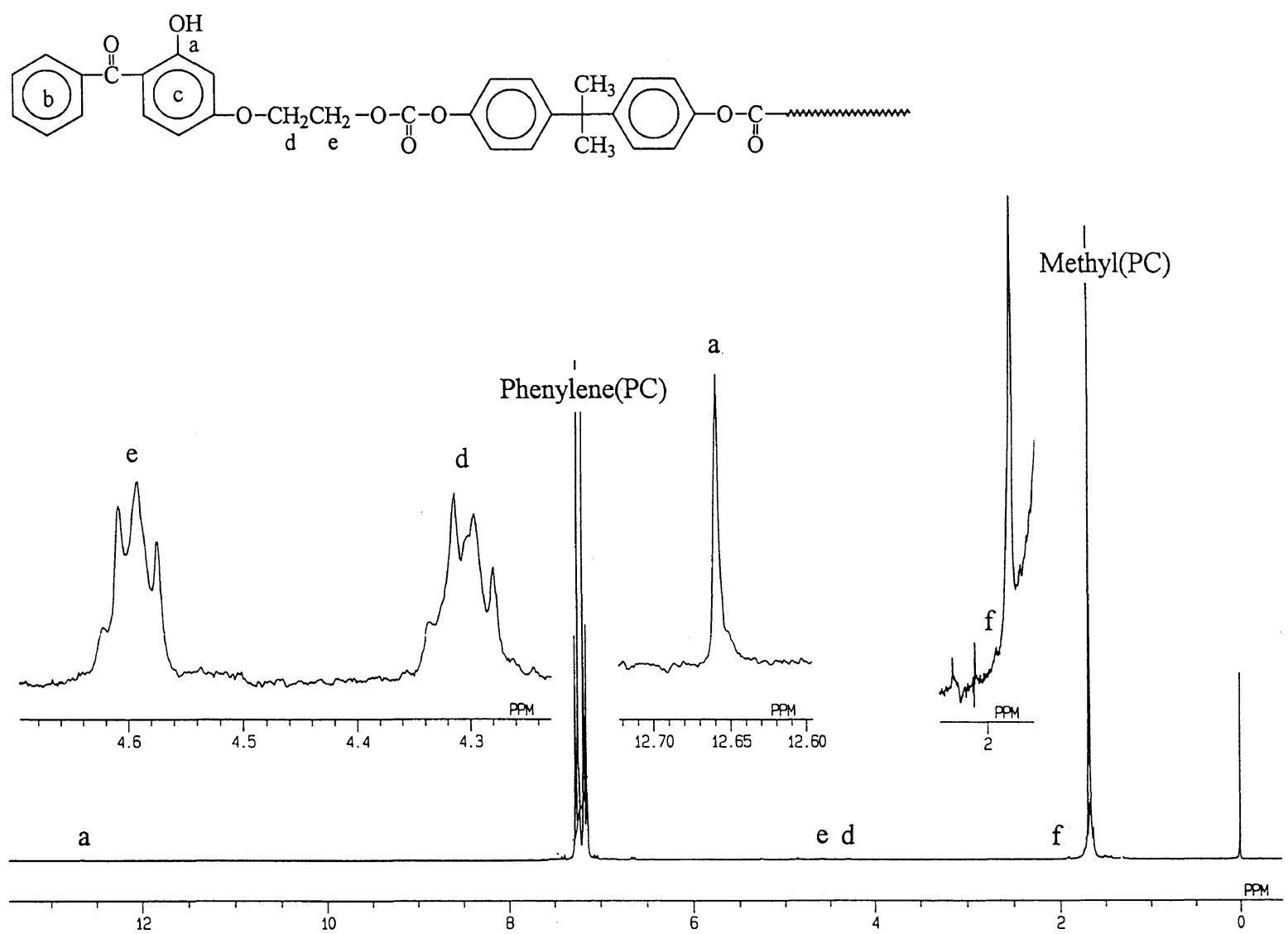

Figure 7. ${ }^{1} \mathrm{H}$ NMR spectra of the product (solvent: $\mathrm{CDCl}_{3}$ ).

Table I. Reactions of PC with HHEBP

\begin{tabular}{|c|c|c|c|}
\hline \multirow{3}{*}{ Instrument } & \multicolumn{2}{|c|}{ НHЕВР } & \multirow{3}{*}{$\begin{array}{c}\text { Conversion } \\
\%\end{array}$} \\
\hline & \multirow{2}{*}{$\begin{array}{c}\text { Added } \\
\mathrm{mol} \%\end{array}$} & \multirow{2}{*}{$\begin{array}{c}\text { Reacted } \\
\mathrm{mol} \%\end{array}$} & \\
\hline & & & \\
\hline$U^{b}$ & 0.987 & 0.626 & 63.4 \\
\hline $\mathrm{GPC}^{\mathrm{c}}$ & 0.987 & 0.633 & 64.1 \\
\hline NMR & 0.987 & 0.657 & 66.6 \\
\hline
\end{tabular}

${ }^{\text {a }}$ Reaction of PC $(60.0 \mathrm{~g})$ with HHEBP $(0.6 \mathrm{~g})$ was carried out in the presence of $\mathrm{FeCl}_{3}(0.6 \mathrm{mg})$. ${ }^{\mathrm{b}}$ Estimated at $325 \mathrm{~nm}$. ${ }^{\mathrm{c}}$ Measured with UV detector at $325 \mathrm{~nm}$.

phenylene protons and the singlet peak seen at $1.68 \mathrm{ppm}$ was due to the methyl proton of PC. The signals at 3.96 and $4.12 \mathrm{ppm}$ might come from the methylene protons of HHEBP. Those at 1.96 and $12.66 \mathrm{ppm}$ originated from the alcoholic and the phenolic hydroxy protons of HHEBP. In the ${ }^{1} \mathrm{H}$ NMR spectra of the product shown in Figure 7, signals due to PC were also recorded at the same positions as signals due to the control specimen. Those due to two different protons shifted from $4.12 \mathrm{ppm}$ and $3.94 \mathrm{ppm}$ to $4.31 \mathrm{ppm}$ and $4.60 \mathrm{ppm}$, respectively. The signal at $1.96 \mathrm{ppm}$ caused by the alcoholic hydroxy protons thoroughly disappeared although the signal of phenolic hydroxy protons was still discerned in the spectrum. No change was confirmed in the intensity ratio of the signal from the phenolic hydroxy protons of HHEBP to that from the methylene protons of HHEBP, indicating that the phenolic hydroxy group was not related to the transesterification reaction at all. As sum-

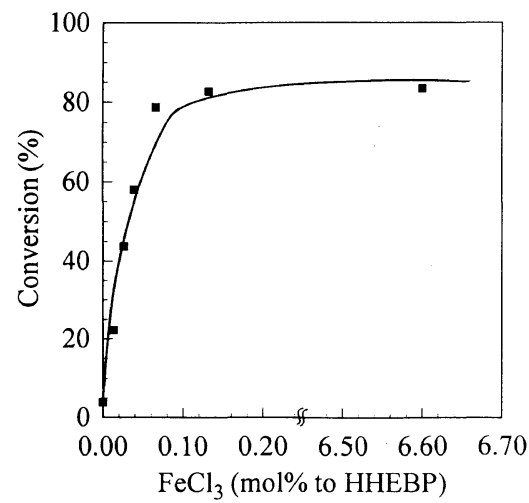

Figure 8. Effects of $\mathrm{FeCl}_{3}$ on the conversion of HHEBP reacted at $255^{\circ} \mathrm{C}$ at $30 \mathrm{rpm}$ for $10 \mathrm{~min}$.

marized in Table I, from comparison of the signal intensity of phenolic hydroxy protons and that of methylene protons, the conversion of HHEBP was estimated to be $67 \%$, which is consistent with that estimated by UV study (absorption).

Figure 8 shows the conversion of HHEBP as a function of the amount of catalyst $\mathrm{FeCl}_{3}$. Apparently $\mathrm{FeCl}_{3}$ is very effective for transesterification between $\mathrm{PC}$ and HHEBP. The conversion increases very remarkably with $\mathrm{FeCl}_{3}$ up to $0.1 \mathrm{~mol} \%$ of HHEBP and reaches $80 \%$ and then levels off. The time-conversion relation shown in Figure 9 indicates that the reaction reaches an equilibrium within $5 \mathrm{~min}$ when conducted at $255^{\circ} \mathrm{C}$ in the presence of $\mathrm{FeCl}_{3}$. The reaction in the rheometer was carried out for 10 min at 252,273 and $294^{\circ} \mathrm{C}$ to elucidate the effects of temperature on conversion. Apparently the 


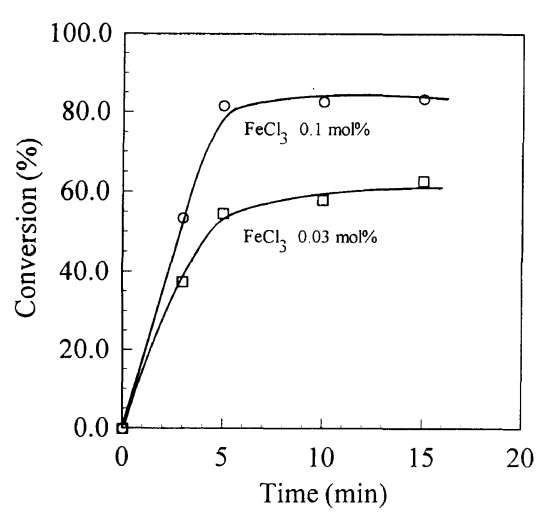

Figure 9. Time-conversion plots of the reaction of PC with HHEBP at $255^{\circ} \mathrm{C}$ at $30 \mathrm{rpm} ; \mathrm{FeCl}_{3}, 0.03 \mathrm{~mol} \%(\square)$ and $0.10 \mathrm{~mol}^{\%}(\mathrm{O}$ ).

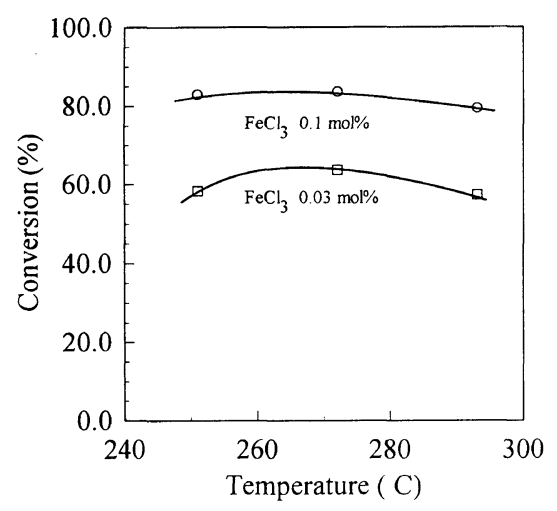

Figure 10. Effect of temperature on conversion of HHEBP reacted in the presence of $0.03 \mathrm{~mol} \%$ ( $\square$ ) and $0.10 \mathrm{~mol} \%$ (O) of $\mathrm{FeCl}_{3}$ at $30 \mathrm{rpm}$ for $10 \mathrm{~min}$.

conversion was almost independent of the reaction temperature, as was shown in Figure 10.

Conversion barely increased with decreasing melt viscosity due to upward temperature but the amount of HHEBP in the system decreased by elimination of vaporization. Because the reaction was performed in the torque rheometer which allowed elimination of vaporized HHEBP. Therefore conversion below 80 mol\% may be attributed to the loss of HHEBP during the reaction. Actually the data obtained by UV and GPC analyses showed that about $15 \%$ of HHEBP was lost from the reactor, when the reaction was carried out for $5 \mathrm{~min}$ at $255^{\circ} \mathrm{C}$.

HHEBP remaining in the torque rheometer reacted with $\mathrm{PC}$ in a quantitative yield.

The conversion is plotted against reaction temperature in Figure 9. Apparently the conversion is merely dependent on the amount of $\mathrm{FeCl}_{3}$ added but almost independent of the temperatures. The transesterification reached equilibrium within $5 \mathrm{~min}$.

Films prepared from the control and product were subjected to extraction of unreacted HHEBP with methanol, a good solvent for HHEBP but a nonsolvent for PC. After being immersed in methanol at room temperature for $12 \mathrm{~h}$, HHEBP remaining in films was compared to that in both specimens. The results are summarized in Table II. Though HHEBP in the control specimen almost completely dissolved out of the films, that in the product was not extracted at all and settled down in PC, indicating HHEBP in the product to be chemically bonded with PC.
Table II. Extraction of HHEBP with methanol ${ }^{\mathrm{a}}$

\begin{tabular}{lllll}
\hline & & \multicolumn{2}{c}{ HHEBP } & \\
\cline { 3 - 4 } Run & Samples & \multicolumn{2}{c}{ mol\% } & $\begin{array}{c}\text { Ratio } \\
\text { after/before }\end{array}$ \\
\cline { 3 - 4 } & & Before & After & \\
\cline { 3 - 4 } 1 & Control $^{\mathrm{b}}$ & 1.02 & 0.034 & 0.034 \\
2 & ${\text { Product } 1^{\mathrm{c}}}_{3}$ & 0.184 & 0.184 & 1.00 \\
4 & ${\text { Product } 2^{\mathrm{c}}}$ & 0.528 & 0.528 & 1.00 \\
& Product $3^{\mathrm{c}}$ & 0.987 & 0.987 & 1.00 \\
\hline
\end{tabular}

${ }^{\mathrm{a}}$ Carried out at room temperature for $12 \mathrm{~h}$. ${ }^{\mathrm{b}}$ Film prepared from control. ${ }^{\mathrm{c}}$ Films prepared from products purified by reprecipitation to remove HHEBP unreacted.

Table III. Weathering test

\begin{tabular}{cclc}
\hline \multirow{2}{*}{ Run } & Sample & $\begin{array}{c}\text { Appearance } \\
\text { of film }\end{array}$ & Time exposed \\
\cline { 3 - 3 } & & & $\mathrm{h}$ \\
\hline 1 & PC $^{\mathrm{a}}$ & Deep cracks & 144 \\
2 & Control $^{\mathrm{b}}$ & Small cracks & 216 \\
3 & ${\text { Product } 3^{\mathrm{c}}}^{\mathrm{S}}$ & Unbroken & 216 \\
\hline
\end{tabular}

${ }^{a}$ Commercial PC. ${ }^{b}$ Film prepared using control. $\quad{ }^{\mathrm{c}}$ Film prepared with product.

These films were subjected to a weathering test to estimate the stabilizing effect of HHEBP bonded at the terminals of PC. The results are summarized in Table III. After 9 days exposure, the films prepared from the reaction product were still unchanged while the short and shallow cracks generated on the surface of the films made from control specimen in which HHEBP was dispersed in the matrix of PC. The films prepared from PC alone without HHEBP showed may deep surface cracks within a week.

\section{CONCLUSION}

In this model study of reactive processing, Bisphenol A polycarbonate was modified with 2-hydroxy-4-(2hydroxyethoxy)benzophenone via the transesterification of PC and a benzophenone derivative in a torque rheometer. The reaction rapidly proceeded as expected and the conversion of the benzophenone derivative employed exceeded $80 \mathrm{~mol} \%$ within $5 \mathrm{~min}$, at $255^{\circ} \mathrm{C}$ or higher in the presence of $\mathrm{FeCl}_{3}$. Extraction of solid films revealed that the benzophenone derivatives connected at chain ends were hardly removed within $12 \mathrm{~h}$ while those in PC rapidly bleed out from PC.

\section{REFERENCES}

1. D. Freitag, U. Grigo, P. Müller, and R. Nouvertné, in "Encyclopedia of Polymer Science and Engineering”, 2nd ed, Vol. 11, J. I. Kroschwitz, Ed., Wiley, New York, N.Y., 1985, p 648.

2. V. Serini, in 'Ullmann's Encyclopedia of Industrial Chemistry," 5th ed, Vol. A21, W. Gerhartz, Ed., Verlag Chemie, Weinheim, FRG, 1985, p 207.

3. J. P. Mercier, J. Appl. Polym. Sci., 9, 447 (1965).

4. J. Schaefer and E. O. Steskal, Macromolecules, 18, 368 (1985).

5. B. Hartmann and G. F. Lee, J. Appl. Polym. Sci., 23, 3639 (1979).

6. D. W. Fox in "Kirk-Othmer Encyclopedia of Chemical Technology," Vol. 18, R. E. Kirk and D. F. Othmer, Ed., Wiley, New York, N.Y., 1985, p 479. 
7. A. Factor, W. V. Ligon, and R. J. May, Macromolecules, 20 2461 (1987).

8. C. A. Pryde, in "Polymer Stabilization and Degradation," P. P. Klemchuk, Ed., ACS Symposium Series No. 280, American Chemical Society, Washington, D.C., 1985, Chapter 23, p 329.

9. A. Rivaton, D. Sallet, and J. Lemaire, Polym. Degrad. Stability, 14, 1 (1986).

10. Y. Fukuda and Z. Osawa, Polym. Degrad. Stability, 32, 285 (1991).

11. Y. Fukuda and Z. Osawa, Polym. Degrad. Stability, 34, 75 (1991).

12. A. Factor, in "Polymer Durability, Degrad. Stabilization, and Lifetime Prediction", R. L. Clough, Ed., Advances in Chemistry Series No. 249, American Chemical Society, Washington, D.C., 1996, Chapter 5, p 59

13. A. Gupta, R. Liang, J. Moacanin, R. Goldbeck, and D. Kliger, Macromolecules, 13, 262 (1980).
14. D. T. Clark and H. S. Munro, Polym. Degrad. Stability, 5, 23 (1982).

15. Z. Osawa, "Deterioration and Stabilization of Polymeric Materials," (in Japanese), CMC, Tokyo, 1990, p 146.

16. G. Scott, Ed., "Atmospheric Oxidation and Antioxidants," Vol. II, Elsevier Science Publishers B. V., Amsterdam, 1993, Chapter 5, p 279.

17. T. Sakai, Plastic Age (in Japanese), 39, 125 (1993).

18. B. K. Kim and C. H. Choi, Polymer, 37, 807 (1996).

19. Y. Kasuya, Y. Watanabe, T. Kikuchi, T. Kuramochi, S. Teramachi, and M. Ibonai, Seikei-Kakou (in Japanese), 5, 205 (1993).

20. W. Michaeli, H. Höcker, U. Berghaus, and W. Frings, J. App. Polym. Sci., 48, 871 (1993).

21. N. P. Stuber and M. Tirrell, Polym. Process Eng., 3, 71 (1985).

22. K. J. Ganzeveld and L. P. B. Janssen, Polym. Eng. Sci., 32, 467 (1992). 